\title{
A crítica da loucura e a práxis poética da necessidade existencial: estudo de caso da ONG Inverso
}

The critique of the madness and the poetical praxis of the existential need: a case study of the NGO Inverso

\author{
Vicente de Paula Faleiros* \\ Thiago Petra da Motta Campos**
}

\begin{abstract}
Resumo:
Neste texto, discute-se a relação entre a expressão da pessoa considerada louca, no contexto da sociedade e da intersubjetividade, na dinâmica da ONG Inverso (Instituto de Convivência e Recriação do Espaço Social em Saúde Mental). A poética da intervenção articula o instituído ao instituinte das relações do coletivo na sociedade. O objetivo é analisar as segregações da loucura e do louco e o processo emancipatório da crítica e da prática poética com pessoas que frequentam o espaço da ONG, junto com a revisão da literatura correspondente, com reflexão crítica da experiência da Inverso como processo inverso ao modelo manicomial. A metodologia deste trabalho foi construída a partir de uma reflexão sobre saúde mental, loucura e cultura, e da observação direta do cotidiano da ONG Inverso, por 10 anos, como processo instituinte. $O$ principal resultado desse processo foi a evidência de condições possíveis para a efetivação de um paradigma antimanicomial de inclusão, cidadania, singularidade na promoção da saúde mental.
\end{abstract}

Palavras-chave: Antimanicomial. Poética da expressão. Loucura. Singularidade.

\begin{abstract}
:
This text discusses the relationship between the expression of the persons considered mad in the context of society and intersubjectivity, in the dynamic of NGO Inverso (Institute of Coexistence and Recreation Social Space in Mental Health). The poetic of intervention articulates the instituted to instituting relations of the collective organization. The objective is to analyze the segregation of madness and the mad and witness the emancipatory process of criticism and poetic practice with people attending the NGO space, with a review of relevant literature, with analysis of the experience as the Inverse/reverse process in the asylum model. The study methodology was constructed from the analysis of texts on mental health, madness and culture and direct observation of daily Inverse NGO for 10 years as instituting proceedings. Shows the dynamics of practices of the individual and collective expression of uniqueness and existential necessity of subjects in coexistence.
\end{abstract}

Key-words: Antimanicomial. Poetics of the expression. Madness. Singularity.

* Professor emérito da UnB e docente da UCB. PhD em sociologia. E-mail: vicentefaleiros@terra.com.br

** Psicólogo, mestre em psicologia pela Universidade Católica de Brasília, E-mail: thiagopetra@yahoo.com.br 


\section{Introdução}

A expressão da pessoa considerada louca, no contexto da sociedade e da intersubjetividade, a partir da práxis da ONG Inverso (Instituto de Convivência e Recriação do Espaço Social em Saúde Mental) e seus desdobramentos, é a discussão central do estudo apresentado neste artigo. Inverso, neste contexto, tem o significado de "inverso do manicômio", pois articula o instituído ao instituinte nas relações do coletivo na sociedade envolvente. O objetivo do estudo desenvolvido, aqui apresentado, foi analisar a inclusão social do chamado louco e testemunhar o processo emancipatório da crítica e da prática poética com pessoas que frequentam o espaço da ONG. Para isso, faz-se, inicialmente, uma revisão da literatura sobre a segregação da loucura e uma análise da experiência da Inverso como processo crítico ao modelo manicomial, incluindo a perspectiva da reforma psiquiátrica.

A metodologia para a elaboração deste ensaio foi construída a partir da análise de textos sobre saúde mental, loucura e cultura, dentre outros que dialogam com o tema, e da observação direta do cotidiano da ONG Inverso como processo instituinte. A observação participante levou em conta a presença contínua dos autores do texto no dia a dia da organização, como voluntários de atividades de oficinas. As anotações do trabalho foram feitas periodicamente e em reuniões da equipe, no período entre 2003 e 2014.

O estudo compreende seis áreas temáticas que traduzem os referenciais adotados e a prática da Inverso. Primeiramente, trata-se do conceito de loucura, do lugar do louco e da dialética e da poética do inverso. Em seguida, são destacadas cinco formas estratégicas postas em movimento, articuladas entre si, na práxis da Inverso: a relação com a cultura; a relação com a autonomia, a democracia e o poder; o exercício da liberdade e da criatividade; a expressão do sentimento e do sofrimento; e a construção da cidadania, da rede e da solidariedade.

\section{Inverso: espaço de convivência, liberdade e participação versus prisão da loucura}

A Inverso coloca-se como um espaço de convivência e de recriação do contexto social. Este espaço resulta da luta antimanicomial, que tem como uma de suas fundamentações o Relatório sobre a Saúde no Mundo de 2001- Saúde Mental: nova concepção, nova esperança (ORGANIZAÇÃO MUNDIAL DE SAÚDE, 2001), e da Lei 
10.216/2001, que dispõe sobre a proteção e os direitos das pessoas portadoras de transtornos mentais e redireciona o modelo assistencial em saúde mental.

A luta antimanicomial do Século XX inscreve-se, substancialmente, na experiência italiana liderada por Franco Basaglia (1985), desencadeada no início dos anos 60. Na ótica manicomial, a loucura foi considerada como anormalidade, articulando-se com o outro lado da mesma moeda, ou seja, seu enquadramento institucional e político pelo hospício, onde se produz a sujeição dos "anormais" para serem "curados", normalizados. Cura, do ponto de vista da normalidade dominante, significa submissão e adaptação. Dessa forma, o sintoma da anormalidade é a insubmissão, e a mediação da normalidade é a violência.

A violência dos manicômios tem sido efetivada pelo exercício do poder institucional de enquadramento (BASAGLIA, 1985) e pelo procedimento classificatório da submissão ao saber instituído (FALEIROS, 2011), que parte do pressuposto estabelecido da assimilação da loucura à doença. O hospício já foi também lugar da separação ou segregação dos classificados como endemoniados, bestas, inumanos, sem-razão, anarquistas, perversos e violentos. Era preciso classificá-los como agressivos, descontrolados e incapazes, para amordaçá-los, agrilhoá-los, cerceá-los, pô-los entre grades, também simbólicas. Apesar da formulação de um "projeto" de cura ou normalização, estes eram considerados incuráveis e, até mesmo, contagiosos. No Dicionário Filosófico de Voltaire $(2003$, p. 361), há a referência de que a loucura é doença do cérebro e forma de agir fora da normalidade, incurável, como se pode observar na citação a seguir:

Chamamos de loucura a essas doenças dos órgãos do cérebro que impedem um homem de pensar e de agir como os outros. Não podendo gerir seus bens, é, interdito; não podendo ter ideias de acordo com a sociedade, é excluído; se for nocivo, é enclausurado; se for furioso, trancafiam-no.

O louco não é somente considerado sem razão e sem produtividade, mas, em si mesmo, problema insondável e insolúvel, patológico. O inverso desta perspectiva será, portanto, considerá-lo humano, capaz e criativo. Vale resgatar o sentido de pathos, explorado por Martins (1999, p. 66):

O conceito de pathos traz consigo possibilidades e problemas mais amplos que o sentido de doença, não fazendo parte de um só campo de estudos como a palavra "patologia" indica. Investigando-se com mais cuidado percebe-se que se 
trata de uma dimensão essencial humana. O pathos seria compreendido como uma disposição (stimmung) originária do sujeito que está na base do que é próprio do humano. Assim, pathos atravessa toda e qualquer dimensão humana, permeando todo o universo do ser.

A loucura insere-se na cultura do Ocidente, seja como incapacidade de resposta à situação de normalidade, como suposta violação de normas ou como marginalidade à sociedade de consumo e de produção da mais-valia. Em sua anamnese, era preciso encontrar uma causa individual à qual se daria uma classificação e, depois, um remédio, ou um remedo ou mesmo um remendo, na visão positivista biomédica. A anamnese da loucura como doença prende-a na armadilha da classificação dos sintomas de incapacidade pessoal, familiar e social.

O inverso dessa visão incapacitante é o entendimento de loucura a partir de sua história sociocultural e como necessidade existencial. Com efeito, o manicômio e suas práticas negam não só a condição social da pessoa, mas sua própria necessidade existencial. Basaglia, segundo Kirchmayer (2012), coloca como fundamento da luta antimanicomial a ênfase na experiência vivida dos fatos e situações numa crítica "da razão psiquiátrica" como forma de conhecimento e classificação da loucura.

A necessidade existencial funda-se na prática da liberdade ou na poética da vida, no sentido de fazer-se protagonista da história e de sua história. As determinações objetivas não são negadas, mas assumidas. Como lembra Sartre (1979, p. 30), "o existencialismo, como o marxismo, aborda a experiência para nela descobrir sínteses concretas", acrescentando ainda que, "para nós, o homem caracteriza-se antes de tudo pela superação de uma situação, pelo que ele chega a fazer daquilo que se fez dele, mesmo que ele não se reconheça jamais em sua objetivação." (SARTRE, 1979, p. 78).

As condições do chamado tratamento do louco são lembradas por Saraceno (2001) como centradas na violência e no confinamento, o que resultava em ineficácia. Para ele, "a condição real da média dos pacientes psiquiátricos, internados ou não em qualquer lugar do planeta é dramaticamente igual: violência e miséria nas instituições psiquiátricas totais, abandono e resposta farmacológica pesada" (SARACENO, 2001, p. 20).

Desconsiderava-se a cidadania e a rede comunitária da pessoa como condições e projeto de vida. Desse modo, o manicômio e suas práticas representavam a negação dos direitos, da voz, da expressão, da rede social do louco, aprisionado pelos muros, pela 
classificação e pela medicalização da doença, pois era considerado como irracional, incapaz, inferior e anormal, devendo ser submetido, exclusivamente, ao poder psiquiátrico e institucional.

Por sua vez, a Inverso apropria-se dessa crítica, postulando a possibilidade de se construir uma convivência aberta à diversidade de relações e formas de ser, à expressão da necessidade existencial e da liberdade e, ao mesmo tempo, criticando a normalidade imposta pelo poder hegemônico em sua estruturação capitalista, consumista e individualista.

Assim, toma-se como desafio (re)pensar a loucura e o louco sem os estigmas do preguiçoso, que não trabalha e não está disponível para o capital, do estranho que não fala a linguagem dominante, e do perigoso que rejeita as regulações convencionais. Ressaltase que é um desafio desenvolver uma prática poética de expressão da palavra, do afeto e da autonomia, articulando-as, ao mesmo tempo, à alteridade e à singularidade adormecida.

A proposta de prática da poética social da Inverso é acolher o ser humano em sua necessidade existencial, no seu modo de ser peculiar, articulado à cidadania e à complexidade das relações e das redes sociais virtuais, na sociedade contemporânea.

A prática poética lida não apenas com as interpretações do que é dado, mas com a geração de possibilidades nas trocas sociais, pois, nas trocas sociais, as pessoas percebem e exercitam o projeto de vida de forma digna e saudável. Nessa perspectiva, a prática das artes plásticas, cênicas, musicais, da dança, da poesia e da culinária tornam-se uma forma de linguagem e de comunicação com o outro, de descoberta de si, de civilidade e integração social, além de possibilitarem a ressignificação do estigma, do sofrimento e da banalização do psicofármaco.

A poética crítica tem como perspectiva o aprofundamento da relação democrática, no dia a dia, para que se possa compreender e levar em conta a subjetividade e a singularidade em suas formas mais abrangentes e não classificatórias, de modo a articular o conhecimento com a prática, sem o a priori da academia, sendo um contraponto à hermenêutica dominante dos sintomas irruptivos da chamada normalidade. Hoffman e Pakman (2007, p. 134) ressaltam que a: 
Poética é uma prática construtiva, que ao contrário de buscar significados em comportamentos de outra forma irracionais, anormais ou enigmáticos, assume que todos os comportamentos são socialmente viáveis, efetivos (na medida que causam efeitos e afetam outros) e suscetíveis de interpretações com significado, focando e tornando explícitos os mecanismos que os fazem viáveis, efetivos e interpretáveis de modo significante.

Dessa forma, a poética se inscreve num contexto em que o ser humano é considerado em sua multidimensionalidade, em seu modo peculiar de ser, articulado à complexidade das relações sociais mais gerais, particularizadas nos micro-contextos.

Por essa via da poética, as interpretações são dadas em um contexto histórico vigente no capitalismo, que precisa ser sempre explicitado na própria dinâmica na qual se inscreve, em uma perspectiva de (re)criação desse contexto e das relações da pessoa consigo, com a alteridade e com mundo. Nesta perspectiva, a Inverso tem sempre colocado os participantes em seu contexto e em sua história, onde podem ressignificar suas trajetórias. A seguir, são analisados os temas que ressaltam a articulação da experiência com a teoria.

\section{Ressignificação da identidade na diversidade e na inclusão cultural}

A cultura dominante do manicômio é a que aprisiona a loucura e a diversidade humana pelo viés do sintoma. O sintoma passa a ser o objeto da cura, da normalização, da higienização, com a "solução" sendo dada por alguém de fora, que intervém de forma compulsória. O oposto dessa prática pensa e cuida da pessoa em relação ao complexo e multidimensional contexto político, social, econômico e espiritual, e não apenas com base no sintoma.

No contexto cultural é que se define a expressão e o simbolismo do sintoma (GEERTZ, 1989). A loucura não é um sintoma, nem apenas um fragmento da vida social, mas um modo legítimo de ser. É uma necessidade existencial de liberdade que não se restringe a diagnósticos classificatórios e prescrições médicas. O diagnóstico tradicional implica na invasão do outro. Para Foucault (1977), tal procedimento se inscreve no princípio da higienização social, que busca tornar as pessoas dóceis e úteis. Faleiros (2011) assinala que saber e poder são articulados como espaços de dominação, combinados com lugares de exclusão. Os diagnósticos tornam a loucura objeto de controle, pois remetem ao estigma de incapacidade e periculosidade. Nota-se que o critério técnico-científico tradicional tenta 
eliminar o que é individual e singular para reter leis gerais e identidades simples e fechadas (MORIN, 2011).

$\mathrm{Na}$ Inverso, busca-se entender a pessoa não como doente, inútil, incapaz, ou como mônada isolada, mas em suas relações e diversidade de expressão do sentimento, do desejo, do afeto e da relação entre o delírio e a realidade. Busca-se, ainda, novas formas de expressar o indizível e a singularidade. A cultura da Inverso - oposta às práticas manicomiais - é obra coletiva de si mesma (FALEIROS, 2011), como biografia singular e social de interação, em rejeição à heteronomia dos manicômios.

A história contada por alguns frequentadores da Inverso é a narrativa de suas internações ${ }^{1}$. A memória de sua vida não é a da decisão sobre si, mas da decisão que os outros tomaram sobre si, internando o não outro desejado. Os símbolos da biografia são, assim, os lugares da exclusão. Por outro lado, na Inverso, os diversos frequentadores sentem-se protagonistas da vida, pois sua potencialidade criativa é estimulada, assim, fogem da total submissão. Nesse sentido, conforme Winnicott (1975, p. 95):

É através da percepção criativa, mais do que qualquer outra coisa, que o indivíduo sente que a vida é digna de ser vivida. Em contraste, existe um relacionamento de submissão com a realidade externa, onde o mundo em todos seus pormenores é reconhecido apenas como algo a que ajustar-se ou a exigir adaptação. A submissão traz consigo um sentido de inutilidade e está associada à ideia de que nada importa e de que não vale a pena viver a vida.

A prática poética do agir criativo abre a possibilidade de o indivíduo encontrar e interagir com novos e inexplorados fenômenos psíquicos, numa articulação da convivência e da cultura, para uma transformação recíproca dos frequentadores, dos estagiários e dos profissionais voluntários. Assim, o espaço da Inverso é o da diversidade humana, o que inclui a expressão da loucura, sem tutela. Por exemplo, nesse espaço, os frequentadores possuem a chave para o livre acesso e sentem-se à vontade para fazer diversas atividades, sendo que todas as experiências brotam da própria demanda da pessoa.

Os estagiários e os profissionais voluntários são chamados pelos seus nomes- e não como doutores ou superiores -, não utilizam jalecos ou crachás de identificação, não há prontuários, carimbos, folha de ponto e demais instrumentos burocratizantes. Não é um

\footnotetext{
${ }^{1}$ Há um frequentador que tem 29 anos de idade e um histórico de 28 internações.
} 
lugar de tratamento formal, onde se promete a cura, mas um espaço de convivência com base na práxis poética, no fomento cultural e na aprendizagem concreta da diversidade. Não há uma classificação homogênea dos frequentadores como "doentes", mas como cidadãos. Ali a equipe está, unicamente, comprometida com o encontro da singularidade e do inusitado, com a reinvenção da forma de trabalhar e a revisitação de teorias e da concepção de subjetividade. Observa-se que é por meio das relações interpessoais e de um ambiente acolhedor que se fornece ao outro as condições básicas necessárias para o desenvolvimento de seu projeto de vida, o que gera maior autonomia e democracia na construção de um sentido para a vida.

\section{Teoria e prática da construção da autonomia e da democracia}

O oposto da prática manicomial sustenta-se na práxis democrática e na autonomia relacional. Essa práxis está comprometida com a distribuição igualitária de poder na vida social, sendo o homem uma construção social introjetada (VIGOTSKI, 1999). Portanto, vivese sempre o dilema da relação de independência e da autonomia frente às normas estabelecidas.

A imensa pressão para viver dentro das normas resulta da domesticação e do conservadorismo, cuja consequência é uma vida restrita ou acomodada. Para Vigotski (1999), efetivamente, surpreende o quanto é limitado o número de percepções, sentimentos e atos que o homem atual pode experimentar e realizar. Na visão de Dummar (1999), o homem tem a opção de viver num plano reduzido, ou seja, atendendo, simplesmente, apenas suas necessidades instintivas e vivendo uma vida acomodada em seu meio social e familiar. "Assim, por certo, sentirá o aguilhão da angústia existencial a reclamar tudo o que ele poderia ter feito e realizado, mas que se recusou, truncando sua criatividade" (DUMMAR, 1999, p. 34).

O louco, enfeixado e enfaixado pelo pré-conceito da doença, é considerado fora do normal, esquisito, sem participação, alguém que vive à margem, incapaz de ter autonomia ou de construir autonomia coletiva. Está, assim, submetido à heteronomia, pois, ao não ter acesso à normalidade da vida participativa, também não tem acesso à lógica e à produtividade do sistema econômico. A loucura é, segundo Melo (2012), invariavelmente, acuada pela racionalidade, assim, fica emparedada entre os muros das instituições totais e 
gaguejando frases inaudíveis frente aos critérios científicos e socialmente estabelecidos. Critérios que abafam e desqualificam a voz do louco até silenciá-lo. Morin (2011, p. 15) aprofunda essa questão, ao afirmar que:

A patologia da razão é a racionalização que encerra o real num sistema de ideias coerentes, mas parcial e unilateral, e que não sabe que uma parte do real é irracionalizável, nem que a racionalidade tem por missão dialogar com o irracionalizável.

Para construir o inverso da normatividade da razão dominante é preciso ir à fonte do humano, ao seu mais profundo lugar, para que se possa compreendê-lo nas relações consigo e com os outros. A ruptura com a norma dominante implica a ressignificação da alteridade e do poder (FALEIROS, 2012), mas implica, também, conversar com o que é considerado irracionalizável. Na Inverso, a crítica das normas dominantes nos coloca diante do processo de construção da autonomia relacional como forma de conviver. Basaglia (1985) menciona que a democratização da psiquiatria implica a realização de assembleias rotineiras, nas quais, os pacientes internos possam, de fato, manifestar seus sentimentos, demandas e propostas, participando ativamente de tudo que envolve o processo terapêutico. A assembleia é um mecanismo de convivência e de decisão coletiva, em que o desejo pode ser falado fora do poder classificatório.

$\mathrm{Na}$ Inverso, as relações entre profissionais, voluntários, estagiários e frequentadores são vividas entre pessoas iguais e não pela ótica da regulação e da performance típica da produtividade capitalista, na qual a cura pela norma e o controle pelo medicamento prevalecem.

Para controlar o louco fora dos hospitais e clínicas psiquiátricas, foi necessário inventá-lo como medicalizável, pois isto dá tranquilidade à sociedade e à família. É inegável que a abordagem biomédica tornou-se a principal forma de tratamento, havendo a rotineira prática do diagnóstico comportamental e de prescrição de psicofármacos. Segundo Collucci, (2011), são duas as principais explicações para o aumento da prescrição de psicofármacos: 1. a busca por "soluções" rápidas para conflitos, ou melhor, a preferência por indicar remédios a investir em terapias de médio ou longo prazos; 2. o assédio da indústria farmacêutica. 
No entanto, reconhece-se, na Inverso, a importância do medicamento como um suporte e complemento terapêutico, mas não como única condição de interagir com a existência da alteridade. Seu uso é, diariamente, trazido à discussão pelos frequentadores, inclusive, sobre seus efeitos colaterais ${ }^{2}$.

\section{O exercício da autonomia criativa e da liberdade de expressão como necessidade existencial}

As pessoas chegam à Inverso com um encaminhamento - público ou privado - ou sozinhas. A pessoa fala seu nome e passa a escolher quando e como quer se integrar ao espaço, sendo sua biografia escutada, com o tempo, pela equipe. A não existência de prontuário é uma medida de não rotulação, de aposta na incerteza, de encontro com a singularidade e de ressignificação da identidade.

A poética social das pessoas em relação à arte articula a singularidade e a necessidade existencial, em um processo que objetiva tornar-se reconhecido em sua expressão, sem a costumeira interpretação e rotulação da produção artística como "arte de louco. "3

Segundo Jung (1991, p. 56), "quando uma obra de arte é interpretada da mesma forma como uma neurose, de duas uma: ou a obra de arte é uma neurose ou a neurose é uma obra de arte. " Pode-se transpor esta citação também para o caso dos tidos quadros psicóticos. Para Langer (2006), quando paramos de nos preocupar com a tentativa de interpretar o artista e nos entregamos, puramente, à obra, não nos defrontamos com um símbolo em geral, mas com um objeto de valor emocional peculiar. Dessa forma, o livre exercício da intuição artística depende, frequentemente, da possibilidade de retirar da mente os preconceitos intelectuais que inibem a responsividade natural das pessoas. Langer (2006, p. 417) ressalta, ainda, que a educação da arte e da emoção é negligenciada, deixada ao acaso, ou considerada banal.

\footnotetext{
Em parceria com a TV Sã - Núcleo de Comunicação Comunitária em Saúde Mental - , a Inverso realizou um vídeo chamado "Efeitos Colaterais: um dia no mundo dos remédios", no qual relativiza o uso e os efeitos dos psicofármacos. Um dos capítulos do livro trata do tema.

${ }^{3}$ As expressões criativas dos sujeitos considerados loucos são comumente chamadas de arte bruta ou arte marginal, ou seja, está livre da influência dos estilos oficiais e das imposições do mercado de arte, porém, não deixa de ser uma outra forma de rotular a ação expressiva.
} 
Numa sociedade não repressiva, essa educação para expressão implica a inseparabilidade da realidade objetiva e da subjetividade (MILNER, 1991). Dessa forma, na Inverso, os impulsos sexuais e agressivos que entram em conflito com as imposições da sociedade não são negados, mas considerados em sua formação simbólica. Nesse sentido, o pintor Vlamink apud Cavalcanti (1978, p. 42) assim se expressou: "as minhas cores são gritos do meu instinto. O domínio da arte remete ao indizível ou ao inaudível da sensibilidade e da emoção. " Rancière (2009) assinala que a partilha do sensível é fundamental para a troca, considerando-se que a arte é comunicação.

$\mathrm{Na}$ Inverso, o trabalho de poesia, desenho, artesanato, mosaico, música é comunicação da emoção, da beleza e do sentimento compartilhado. Não há julgamento do que é feio ou bonito, mas expressão do enlevo, da singularidade e da diversidade. Estimulase, no presente, a liberdade e a capacidade criativa para as realizações futuras, pois a pessoa é um constante vir-a-ser. Por exemplo, os frequentadores C. e S. descobriram-se desenhistas; L. e T., mosaicistas, e esta última também se tornou decoradora; H. e F. são poetas; S. e F. são, agora, ritmistas; cada um desenvolveu sua própria forma de expressão e identidade. A arte como criação e expressão de si e de comunicação de vida é instituinte da Inverso.

O pensamento complexo e a práxis poética consideram insuficientes a clareza, a ordem e o determinismo, pois não se pode programar a descoberta, o conhecimento, nem a ação. Para Morin (2011, p. 80): “O campo da ação é muito aleatório, muito incerto. Ele nos impõe uma consciência bastante aguda dos casos, derivas, bifurcações, e nos impõe a reflexão sobre sua própria complexidade."

Loucura e arte são imprevisíveis e desestabilizam as certezas. Na loucura e na arte, tudo é mutável e complexo, ambíguo e polissêmico. Não nos controlamos e nem temos controle frente à arte. Sentimos comoção, espanto, arrepio, alegria, raiva e diversas outras emoções. A arte gera um modo singular de desejos e afetos, fora do padrão, fora do comércio fabricado.

Um dos pontos fundamentais, na Inverso, é o processo de liberdade e criatividade, ou seja, de produção de sentidos, ações e significados. A arte, assim, é uma eficaz intermediadora entre o mundo interno e externo. Para Martins (2012), a criatividade é 
inerente ao funcionamento do psiquismo, assim, uma forma de linguagem pertencente a todos.

Na Inverso, buscam-se espaços de autonomia criativa e de liberdade de expressão, no que pode ser considerado, paradoxalmente, uma equilibração não normatizadora entre a história pessoal e a dinâmica sociocultural. Como diz Caetano Veloso (1986), na música Dom de lludir: "Cada um sabe a dor e a delícia de ser o que é." Isso quer dizer que, muito além do diagnóstico classificatório, existe uma história pessoal em um contexto sócioeconômico-espiritual-cultural (MORIN, 2011).

Por meio da arte, pode-se oportunizar espaços para encontrar outros sentidos, novos territórios e outros modos de ser e viver, de modo a possibilitar que o indizível seja expresso. Assim, a arte representa um espaço único em que emoções e intuições podem se desenvolver de modo autônomo e autêntico.

A prática dos profissionais da Inverso cria oportunidade e proporciona a transformação da condição passiva, de mero receptor de informações e executor de normas, para a posição de emissor ativo e expressivo do próprio mundo subjetivo. Cria, também, a formação do espectador emancipado (RANCIÈRE, 2008), em condições de conviver com o outro de forma democrática, respeitando as possíveis divergências.

\section{A práxis da expressão do sentimento e do sofrimento}

A estratégia da criatividade não é uma barreira para a negação do sofrimento e da crise vivida, diante da demanda psíquica e social. Na Inverso, a criatividade é, ao mesmo tempo, expressão simbólica do sentimento, da dor, da alegria e de várias emoções. Faz-se um grande esforço para que a expressão do sentimento seja tolerada em sua diversidade, legitimando a convivência. Como exemplo, os frequentadores expressam os efeitos colaterais dos medicamentos na redução da libido e o desejo de namorar, de relacionar-se sexualmente e de expandir a afetividade. Expressar a sexualidade está presente nas poesias, nos desenhos, nas redes sociais, nas conversas e nas manifestações do desejo. A sexualidade não é escondida ou reforçada como tabu, mas é falada e simbolizada. $O$ frequentador $\mathrm{H}$. dedicou poemas para todas as mulheres que passaram pela Inverso; L. faz diversos desenhos eróticos; S. fez cadastro em uma página eletrônica de relacionamento; F. e K. se apaixonaram; A. iniciou namoro com uma frequentadora. Privilegia-se a expressão 
dos diversos temas que envolvem a idiossincrasia e a existência, gerando significado e lugar para as mesmas. Nota-se que os profissionais voluntários - sob supervisão -colocam igualmente seus limites pessoais diante dos temas discutidos, de forma explícita, direta, privilegiando o diálogo e o consenso.

Conforme Valladares (2004, p. 84), "talvez a dificuldade maior seja tomar consciência da limitação humana, mas contraditoriamente da enorme possibilidade de criar e construir, que foi legada ao homem. " A expressão dos símbolos, como salienta Silveira (1992), provoca em nós a formulação de nossas percepções de sentimentos e da realidade, além de provocar a formulação de nossas próprias situações e de nossa biografia. Segundo Castelo Filho (2004), a característica fundamental de todo processo criativo - seja expresso de maneira plástica, literária, musical, cinematográfica ou dramática - é compartilhar a experiência emocional por sua capacidade de expressar o indizível, bem como, de organizar o possível caótico mundo interior e os conflitos com o mundo exterior.

Jung (1991) aborda a questão do significado social da expressão artística também como um processo de autorregulação, na vida das épocas e nações, de modo a preencher uma carência ou ânsia coletiva. Compreende-se que as expressões singulares estão articuladas a um contexto, a uma época, pois o sofrimento se articula às dimensões sociais, culturais e políticas de um momento e de um contexto. De modo amplo, a pessoa configura, em símbolos, a experiência de como é sentir-se vivo, de como é sentir-se dentro de um mundo.

Toda manifestação criativa promove um exercício de liberdade, assim, é uma condição imprescindível aos que têm ou tiveram algum tipo de sofrimento intenso na vida. Schopenhauer (1788-1860) e Nietzsche (1844-1900) foram os pioneiros em ensinar o lugar da criação artística na profunda significação do nenhum sentido da vida. Para eles, o vazio da vida é a verdadeira beleza, imperturbada e despida de alma, da matéria e geradora de arte. A expressão artística tanto embeleza a vida como contribui para que os indivíduos se tornem suportáveis e, se possível, agradáveis uns aos outros. A comunicação do sofrimento, por meio da expressão de si, pela arte, possibilita ver e transcender seu significado (NIETZSCHE, 1983).

As expressões artísticas e culturais fazem parte da luta antimanicomial, como meios de promover a saúde mental e a cidadania. A assistência digna em saúde mental está 
relacionada à possibilidade de criação de vínculos possíveis dentro da lógica e das necessidades das pessoas, e não apenas do profissional de saúde. Precisa-se e deve-se criar espaços de poética social variados que permitam a expressão de sentimentos, emoções e vivências singulares. No entanto, muitos dos profissionais da saúde mental não dispõem de condições de trabalho que lhes permitam a atitude necessária para serem criativos, críticos e humanos ao mesmo tempo. A muralha cartesiana aprisiona o profissional na esfera do pensamento racional e formal, sem lhe permitir dar o devido apreço à ordem do imaginário, do criativo e artístico. Para ser valorizada e exercitada, essa nova ordem "requer um ambiente físico no qual estejamos libertos da necessidade de uma ação oportuna prática imediata; e requer um ambiente mental, tanto na própria pessoa como nas que a rodeiam, de uma tolerância que em certos momentos pode parecer loucura" (MILNER, 1991, p. 230). No item seguinte, desenvolve-se a relação da expressão da subjetividade com o contexto da solidariedade, da cidade e da rede.

\section{Saúde mental na luta, na cidade e em rede}

Por último, mas não menos importante, salienta-se a estratégia da relação da saúde mental com a rede de pessoas e instituições da sociedade. A ONG Inverso é uma junção dessa rede, cuja existência se faz por conexões complexas (FALEIROS, 2010).

A Inverso é uma instituição sui generis, pois é um espaço de convivência e cultura e, também, de luta social. Não é propriamente filantrópica, porém, nem lucrativa, nem remunera seus colaboradores. Não possui financiamento público e está em local cedido, com móveis e eletrodomésticos doados. Há pessoas que colaboram financeiramente, segundo sua disponibilidade, e os profissionais trabalham voluntariamente. Há estagiários de psicologia, serviço social e outras especialidades, supervisionados pelos profissionais da ONG e pelos docentes das respectivas faculdades. Dessa forma, é também um local de referência para a formação em saúde mental e de qualificação da práxis.

A relação da Inverso com a sociedade se faz na perspectiva da luta antimanicomial ${ }^{4}$, pois é contra as práticas manicomiais que permanecem mesmo na ausência do manicômio

\footnotetext{
4 Membros da Diretoria da Inverso já compuseram e, ainda compõem, o Movimento Pró-Saúde Mental do DF e o Conselho de Saúde do Distrito Federal, além disso, participam, constante e ativamente, de conferências, congressos, fóruns e seminários.
} 
arquitetônico. O vínculo da Inverso com os movimentos sociais, pelo fim do manicômio e das práticas manicomiais, visa a promover a convivência entre a alteridade e a cidade, defendendo direitos humanos e cidadania. A cidade é o contexto heterogêneo de atividades comerciais, de lazer, de cultura, de trabalho e de exercício das trocas sociais e políticas.

A cidadania implica um pacto de forças sociais e políticas para se fundar o reconhecimento de responsabilidades e direitos, pois é dever do Estado assegurar a liberdade, a justiça, a redução das desigualdades e a expressão cultural e política com tolerância e ampla manifestação da divergência na democracia (FALEIROS, 2010). A construção da cidadania é um processo histórico de ruptura dos grilhões da opressão, da exploração do homem pelo homem, da dominação de classe, de gênero, de raça e de toda forma de discriminação.

O manicômio e as práticas manicomiais segregam o louco das trocas sociais significativas da sociedade, negam a expressão de sua voz e impedem sua participação, portanto, rejeitam o postulado da cidadania e excluem o louco do exercício de sua liberdade civil e de sua manifestação política. A poética da cidadania do louco implica tanto o exercício da palavra e da expressão, como do protagonismo, da liberdade, da organização e da participação nos movimentos sociais, nas atividades da cidade, além do acesso aos direitos básicos, como benefícios e serviços.

A rede de serviços se articula à atenção primária em um ponto nodal da Inverso, onde circula a informação e existe o suporte fundamental para se viver integrado à cidade, como usar o transporte coletivo, fazer visitas aos centros comercias e gastronômicos, a museus, teatros, cinemas e outros espaços de cultura, ocupando lugares diversos e fugindo do isolamento e da segregação estabelecidas.

Os profissionais e frequentadores, usufruindo de sua liberdade, estão presentes nas manifestações públicas da luta antimanicomial, bem como, nas festas e intervenções urbanas e culturais. As manifestações do dia 18 de maio (Dia Nacional da Luta Antimanicomial), na cidade de Brasília, são discutidas com os frequentadores, inclusive, sua programação e as formas de expressão. Busca-se transmutar o sofrimento psíquico individual em uma luta coletiva, em busca de direitos e de qualidade de vida e bem-estar social. 
No Carnaval, foi criado o Bloco do Rivotril ${ }^{5}$, para denunciar, de forma lúdica e espontânea, a banalização dos psicofármacos. O Bloco desfila na Entrequadra, onde está a ONG, e, em 2014, participou do desfile no Pacotão, local tradicional em Brasília, onde agregou a participação de apoiadores e a sociedade como um todo. Esse projeto contempla oficinas sobre a história do carnaval, a confecção de fantasias e um festival de marchinhas. Atualmente, existe uma oficina de percussão para a criação da própria bateria de samba. A Festa Junina também faz parte da cultura brasileira e do calendário da Inverso, com a tradicional quadrilha, o correio elegante, o casamento caipira e quitutes feitos pelos frequentadores e suas famílias.

A celebração do encontro expressa-se e efetiva-se na recepção do "estranho" que chega, do que vai partir, do que volta e das festas culturais e aniversários. O aniversário da ONG, em 08 de março, é comumente festejado com um almoço coletivo, em que há diversos momentos propícios para a expressão dos presentes, principalmente, dos participantes e seus familiares.

Já a interação, via comunicação digital, se faz pelas oficinas de textos e fotos publicados no Blog e no Facebook; a da comunicação social se fez pelo periódico $O$ CabeSão ${ }^{6}$, e, atualmente, pelaTV Sã ${ }^{7}$, que tem um coletivo que discute projetos, elabora roteiros, realiza filmagens e edição de vídeos, também com a participação dos frequentadores.

É fundamental, nesse contexto, salientar que, sob a liderança de um psicólogo voluntário, a arte da Inverso adentra a cidade, a começar pela área verde do comércio, onde a ONG se encontra. Nesta área, as mesas e bancos de concreto foram revitalizados com mosaico, pintura e colagem pelos frequentadores, que a batizaram de "Esquina da Loucidez", ao somarem as palavras loucura e lucidez. Essa iniciativa de intervenção urbana recebeu o Prêmio Nacional Loucos pela Diversidade, organizado pelo Ministério da Cultura e pela Fundação Oswaldo Cruz.

A expressão pelo mosaico se fez ainda em uma parada de ônibus, para, definitivamente, fixar a diversidade na cidade, referenciando-a na vida urbana em sua

\footnotetext{
5 Fundado em 2011.

${ }^{6}$ O jornal CabeSão teve o nome escolhido pelo coletivo e com a maioria do conteúdo feito por tal. Depois da criação do Blog e do Facebook institucional, o jornal impresso foi desativado.

7 Núcleo de comunicação comunitária.
} 
heterogeneidade. Essa intervenção recebeu o nome de "Loucura Passageira". Determinadas ações têm conseguido veicular as experiências da Inverso nas mídias e nos meios acadêmicos (monografias, dissertações, artigos).

$\mathrm{Na}$ Inverso, trabalha-se com as práticas de intervenção urbana, predominantemente, como uma forma de agir político. Sua ênfase também está na produção de processos de singularização e transformações do cotidiano, que articulam o processo de individuação com o de socialização. O objetivo da intervenção urbana é desestabilizar as estruturas institucionais de dominação e, então, questionar a elitização do espaço público e proporcionar a revitalização da cidade como lugar de diálogo e experiência lúdica. Mazetti (2006) entende a intervenção urbana, que se dá no cotidiano do espaço público, no âmbito de uma micropolítica contemporânea, como um protesto e uma tentativa de afirmação diante do comportamento urbano dominante. Além disso, a intervenção urbana destacase por produzir novas maneiras de o indivíduo ver, sentir, perceber, ser e estar no mundo, apropriando-se e pertencendo à cidade.

A Luta Antimanicomial rejeita o modelo hospitalocêntrico e a instituição total. Podese observar, claramente, que nenhuma instituição consegue atender todas as demandas e dimensões da pessoa em sua complexidade de relações. Nessa perspectiva, apesar de sua inovação criativa, a Inverso se coloca na incompletude institucional e se torna eficaz em um elo com outros serviços substitutivos ao manicômio e suas práticas, compondo uma Rede qualificada e diferenciada. A qualificação diferenciada implica considerar a práxis poética na realização da singularidade e do protagonismo, diante da submissão e da segregação.

A rede primária da família compartilha a responsabilidade do cuidado. No entanto, muitos frequentadores que já passaram por várias internações, ao frequentarem a Inverso, manifestam que preferem viver sozinhos em suas casas, de forma autônoma, mas que também precisam dos serviços especializados de saúde e a integração pela via da educação, do trabalho e das ações expressivas aliadas ao contexto comunitário e urbano. Essa Rede precisa conversar e ser conectada pelo contato de diversos profissionais, bem como, por pesquisas e ações, informações e dinamização, de modo a construir a integração na interdisciplinaridade, com eficácia na perspectiva de promover a cidadania e o bemestar. 


\section{Considerações finais}

Esse trabalho de reflexão mostra que é possível a emergência de práticas críticas ao manicômio e a abertura de um espaço para mudanças e transformações na política cotidiana de atenção ao louco ou à pessoa com necessidade existencial de ser e viver com sua loucura. Não se trata de um modelo ideal, mas de uma prática em movimento, na ótica da luta antimanicomial, ainda "nas margens".

Falar da loucura é falar da sociedade, que é falar da loucura, assim, a loucura tornase social e questiona o status de normalidade. Aliás, que normalidade é pressuposta? $\mathrm{Na}$ relação da sociedade com a loucura e da loucura com a sociedade, há ditames de normalidade e de normalização. No ditame dominante de normalidade, a loucura é desordem e desrazão, é incapacidade e periculosidade. Considerar a loucura como um modo legítimo de ser na vida (ROTELLI, 1990), como uma singularidade, uma necessidade existencial, como o exercício da liberdade e da expressão da pessoa configura-se como uma postura crítica. Traduzir essa postura na prática é o desafio da Inverso. Pensá-la como práxis poética é a tese reflexiva.

No estudo de caso, aqui apresentado, enfrentou-se esses desafios ao se buscar explicar a poética da ação-reflexão em movimento, pois, em um primeiro momento, a Inverso pode aparecer apenas como a virada de um modelo para outro, apenas o contrário, sem que sejam analisadas as contradições em processo. No entanto, ao longo desse estudo, mostrou-se que a poética traduz o contraditório do questionamento do manicômio e das práticas manicomiais, presentes no exercício de uma prática que transforma o cotidiano da vida e a vida no cotidiano, de um grupo de cidadãos, classificados como "doentes mentais", pela ótica manicomial, que vivem a saúde mental na convivência mútua.

Esse modo contraditório de ser pressupõe a desconstrução de um paradigma de poder, de ser humano e de cuidado, construção e dinamização do outro, que, na Inverso, se faz pela dialética poética. A dialética poética implica participação, respeito, democracia, autonomia e expressão da liberdade, da criatividade e da cultura, além do diálogo sobre o sofrimento, no cotidiano, no âmbito de uma Rede comunitária e emancipatória.

A loucura não é vista como um surto e nem como uma estrutura permanente de irracionalidade. É uma necessidade existencial, um modo de ser no mundo, um modo de 
ser humano. Verifica-se que esse modo legítimo precisa ter suporte para ser exercido aliado à cidadania.

Neste estudo, não foram abordados os resultados dessa operacionalização, mas seu processo, como processo das relações de poder compartilhado. A dialética poética do poder compartilhado é condição para que as pessoas criem projetos, tenham o desejo de viver, criem satisfação com a vida e construam sentidos para ela.

A prática, aqui analisada, é entendida como uma práxis política que articula as relações do ser humano com a liberdade, a sociedade, a estética e o sujeito oprimido, a expressão com a convivência, a vida diária com a cidadania, sem separar, cartesianamente, corpo e mente, grito e canto, morte e vida, o contexto e a singularidade. Tal postura contribui para a ressignificação e o fortalecimento da identidade e da cidadania. No entanto, ainda hoje, observa-se o esvaziamento da alteridade e a consequente despersonalização do sujeito com sofrimento psíquico grave. Assim, os ditos loucos não

têm nome, têm diagnósticos. Na Inverso todas e todos têm nomes, histórias e potencialidades.

Enfim, a dialética da poética não é reducionista ou mutiladora, ou seja, não se limita ao medicamento ou a um único serviço, mas considera o contexto, a convivência com respeito às singularidades e, ao mesmo tempo, à cidadania.

\section{Referências}

BASAGLIA, F. A instituição negada. Rio de Janeiro: Graal, 1985.

CASTELO FILHO, C. O processo criativo: transformação e ruptura. São Paulo: Casa do Psicólogo, 2004.

CAVALCANTI, C. A história das artes. Rio de Janeiro: Ed. Rio, 1978.

COLLUCCI, C. Consumo de antipsicóticos cresce entre crianças e idosos. Folha de S. Paulo, São Paulo, 25 jul. 2011. Cotidiano, Saúde, p. 10

DUMMAR, J. F. O complexo criativo: a arte, o inconsciente coletivo e a transcendência. Petrópolis: Vozes, 1999.

FALEIROS, V. P. Cidadania e política. In: LUIZ, D. E. C. Sociedade civil e democracia. São Paulo: Veras, 2010. p. 275-303.

FALEIROS, V. P. Saber profissional e poder institucional. 10. ed. São Paulo: Cortez, 2011. 
FALEIROS, V. P. Um esboço para discutir a relação poder/alteridade/identidade, Brasília: Universidade Católica, 2012. (Texto para discussão. Seminário da Linha de Pesquisa Cultura Contemporânea e Relações Humanas).

FOUCAULT, M. Vigiar e punir. Petrópolis: Vozes, 1977.

GEERTZ, C. A interpretação das culturas. Rio de Janeiro: LTC, 1989.

HOFFMAN, L.; PAKMAN, M. Poética social. In. FERNANDES, L.; SANTOS, M. R. (Org.). Terapia familiar, redes e poética social. Portugal, Lisboa: Climepsi, 2007. p. 127-150.

JUNG, C. G. O espírito na arte e na ciência. 3. ed. Petrópolis: Vozes, 1991.

KIRCHMAYER, R. Critique du corps "fou". L'héritage de Sartre danslapsychiatrie de Franco Basaglia. Lestempsmodernes, Paris, v. 67, n. 668, p. 23, 2012.

LANGER, S. K. Sentimento e forma. São Paulo: Perspectiva, 2006.

MARTINS, F. O que é pathos? Revista Latinoamericana de Psicopatologia Fundamental, São Paulo, v. 2, n. 4, p. 62-80, 1999. Disponível em: <http://www.franmarpsi.com/ artigo_detalhe.aspx?id=30>. Acesso em: 19 jul. 2012.

MARTINS, F. O sujeito pela arte: loucura e psicanálise. 2012. Disponível em: <http://www.franmarpsi.com/artigo_detalhe.aspx?id=30>. Acesso em 2 maio 2012.

MAZETTI, H. M. Intervenção urbana: representação e subjetivação na cidade. Intercom Sociedade Brasileira de Estudos Interdisciplinares da Comunicação. In: CONGRESSO BRASILEIRO DE CIÊNCIAS DA COMUNICAÇÃO - UNB, 29., 2006, Brasília. Resumos... Brasília, 2006. Disponível em: <http://www.intercom.org.br/papers/nacionais/2006/ resumos/R0682-1.pdf>. Acesso em: 2 fev. 2012

MELO, W. Da nau dos insensatos ao círculo antropológico: a obra de arte em história da loucura de Michel Foucault. Cadernos Brasileiros de Saúde Mental, Florianópolis, v. 3, n. 6, p. 65-88, 2012.

MILNER, M. A Loucura suprimida do homem são. Rio de Janeiro: Imago, 1991.

MORIN, E. Introdução ao pensamento complexo. 4. ed. Porto Alegre: Sulina, 2011.

NIETZSCHE, F. W. Humano, demasiado humano. São Paulo: Victor Civita, 1983.

ORGANIZAÇÃO MUNDIAL DE SAÚDE - OMS. Relatório sobre a saúde no mundo 2001: saúde mental: nova concepção, nova esperança. Genebra: OMS/OPAS, 2001.

RANCIÈRE, J. A partilha do sensível: estética e política. São Paulo: EXO experimental org., 2009.

RANCIÈRE, J. Le spectateur émancipé. Paris: La Fabrique Éditions, 2008.

ROTELLI, F. A instituição inventada. In. NICÁCIO, F. (Org.). Desinstitucionalização. São Paulo: Hucitec, 1990. 
SARACENO, B. Manual de saúde mental: guia básico para atenção primária. São Paulo: Hucitec, 2001.

SARTRE, J. P. Questão de método. São Paulo: Difel, 1979.

SILVEIRA, N. O mundo das imagens. São Paulo: Ática, 1992

VALLADARES, A. C. A. (Org.). Arteterapia no novo paradigma de atenção em saúde mental. São Paulo: Vetor, 2004.

VIGOTSKI, L. S. Psicologia da arte. São Paulo: Martins Fontes, 1999.

VOLTAIRE, F. M. A. Dicionário filosófico. Tradução de Pietro Nassetti. São Paulo: Martin Claret, 2003.

WINNICOTT, D. W. O brincar e a realidade. Rio de Janeiro: Imago, 1975. 